\section{CLOUD PHYSICS}

The Physics of Rainclouds

By N. H. Fletcher, with an introductory chapter by P. Squires. Pp. $x+386+6$ plates. (Cambridge: University Press, 1962.) 65s.

7 HE purpose of this book is two-fold, to provide an introduction to the subject for physicists and meteorologists and to act as a reference volume for workers in the subject. It succeeds in both aims. The newcomer to the subject will find an introductory chapter on the dynamics of clouds and a very short chapter devoted to a general survey of the microphysical processes followed by five chapters about water drops. These chapters deal with condensation, condensation nuclei, the microstructure of non-freezing clouds, the growth and coalescence of cloud droplets and the evolution of rain from non-freezing clouds. The next four chapters discuss the ice phase, dealing with nucleation, ice-forming nuclei in the atmosphere, the growth of ice crystals and rain from sub-freezing clouds. There follow two chapters on the artificial modification of clouds and on the production and properties of silver iodide nuclei and finally a sober survey of large-scale rain-making experiments.

In a subject in which rapid progress is being made it is not always easy to assess the significance of new results. Nevertheless, Dr. Fletcher has produced a book which progresses smoothly from the early chapter on condensation to the final, inevitable, chapter on rainmaking. Throughout the book theoretical discussions, experimental results and descriptions of experimental methods are nicely blended. There is only one major omission. The physics of cloud electrification receives only brief mention. The author defends the omission on the grounds of the uncertainty concerning the role of electrification and of the space which would be required to deal with it. For me this is a matter of regret.

The worker in the field of cloud physics will find a bibliography of nearly 600 references with back references to the page in the bo.k. Each of the years 1953-58 contribute between 40 and 50 of these references-striking testimony to the continuing interest in this subject. There is also a very adequate subject index.

The production of the book is up to the usual high standard of the Cambridge University Press.

\section{A. C. Best}

\section{ASTRONOMY IN THE SPACE AGE}

\section{Space Age Astronomy}

An International Symposium sponsored by Douglas Aircraft Company, Inc., August 7-9, 1961, at the California Institute of Technology in conjunction with the XI General Assembly of the International Astronomical Union. Pp. xxi+531. Edited by Armin J. Deutsch and Wolfgang B. Klemperer. (New York and London: Academic Press, 1962.) 118s.

Astronomy and Spaceflight

By G. A. Chisnall and Gilbert Fielder. Pp. $230+12$ plates. (London: George G. Harrap and Co., Ltd., 1962.) 25s. net.

HE classical problem facing an astronomer is that of
perfecting devices for the collection of the maximum
amount of radiation. It is only from the radiation emitted
or reflected by astronomical objects that anything at all
can be known about them. Radiation is the link connect-
ing the remote parts of the universe with ourselves.
Information is carried by the radiation in two ways-
intensity and wave-length. Clearly the more radiation
we can intercept at various wave-lengths the more,
in principle, we will know about the object emitting the
radiation. The amount of radiation collected can be increased by the construction of larger and larger telescopes, this field of endeavour culminating with the 200 -in. Palomar telescope. No corresponding advance could be made in increasing the wave-length range in which observations could be made since the Earth's atmosphere absorbs all except the visible radiation at optical wave-lengths.

With the development of radio astronomy after the War came the first extension of the range of wave-lengths in which it was possible to observe. A big advance in our knowledge resulted, notably the delineation of the structure of the Galaxy. More recently it has been shown that radio telescopes can obtain information from more distant objects than can be detected with optical telescopes. However, radio telescopes can only operate within a limited band of wave-lengths, radiation at each end of the band being stopped in the Earth's atmosphere.

Since the density of the Earth's atmosphere decreases with height so absorption of radiation will decrease with height and so if instruments could be placed at great heights in the atmosphere a wider range of wave-lengths could be studied. To these ends observatories have been built on high mountains and telescopes taken up in balloons. However, modern advances in rocketry have now made it possible to put apparatus in orbits clear of any absorbing region in the Earth's atmosphere and even send probes to the vicinity of neighbouring planets. Such projects have been before astronomers for several years now, and, with the few results to hand, earlier excitement has become a more cautious optimism. It was at this stage that a symposium "Space Age Astronomy" was held in August 1961 at the California Institute of Technology. The book, Space Age Astronomy, contains the 52 papers and a banquet address presented at the symposium. The object of the symposium was to review what had been achieved using satellite techniques and to present and discuss future projects. The proceedings of the symposium were divided into three sections: accom. plishments, current projects and proved techniques (13 papers); desiderata for future astronomical observations from stations in space (solar, interplanetary, galactic and extragalactic phenomena) (16 papers); celestial mechanics problems in the solar system, planetary exploration and related engineering problems ( 23 papers). To cover such a field in approximately 500 pages means that individual contributions are brief. However, bibliographies are provided where appropriate, and by taking several contributions together a fair picture of the state in any given field can be obtained.

It is arguable that edited discussion is of value in such a symposium. Since the state of the subject will have advanced during the interval necessary for publication valuable comments will have been incorporated in projects under way and so it forms no part of the state of the subject at the time of presenting the symposium-namely, August 1961. Of a secondary nature is the question of the way in which the symposium is presented. Academic Press has produced in every way a well-bound, -printed and -illustrated volume but at a very high price for a progress report in such a rapidly advancing subject. While it is to be congratulated on producing the volume quickly, paper covers would have been adequate for the book's useful lifetime.

Of quite a different nature is Astronomy and Space. flight. This is a book for the interested layman who wants to find out a simple explanation of the fundamentals underlying modern achievements in space. The layman must be in a very limited category, however, in order to derive maximum benefit from this book-he must have General Certificate of Education (Advanced Level) mathematics and physics and maintain enough interest to stay the course. The book is not a unified treatment of the whole subject (clearly this would be impossible in the space available) but considers various aspects such as rocket propulsion, theory of orbits, telescopes, 